\author{
Peter Gow \\ University of St Andrews
}

\title{
Steps towards an ethnographic theory of acculturation
}

Commentary to Łukasz Krokoszyński's article, Drunken speech:

A glimpse into the backstage of sociality in Western Amazonia

$\mathrm{K}^{\mathrm{n}}$

rokoszyński's article raises a powerful possibility: an ethnographic theory turation. I take the concept of ethnographic theory from Marcio Goldman, who in turn took it from Bronisław Malinowski. In Coral Gardens and their Magic, Malinowski wrote,

If we understand by 'translate' the finding of verbal equivalents in two different languages, this task is impossible, and the Italian adage traduttore, traditore holds good. Translation in the sense of defining a term by ethnographic analysis, that is, by placing it within its context of culture, by putting it within the set of kindred and cognate expressions, by contrasting it with its opposites, by grammatical analysis and above all by a number of well-chosen examples - such translation is feasible and is the only correct way of defining the linguistic and cultural character of a word. (Emphasis in the original [1935, vol. 1: 17])

Helena Malinowska Wayne once told me that her father considered Coral Gardens and their Magic to be his most important work of all, but still only the prolegomenon to the really important book he was planning on the Trobriand people. What that book would have been, we will never know, but that this man considered his extraordinary early books on the Trobriand people, held as canonical texts by generations of later anthropologists, as mere dry runs at a genuine science of anthropology, clearly shows that he had a very different vision of what lay up ahead than he is generally credited with.

The core problem for Malinowski in Coral Gardens and their Magic was the Kiriwinan word buyagu. What does this word mean? Malinowski goes for 'garden', but that is simply the start. Marcio Goldman's distinctive contribution to the concept of ethnographic theory has been to press it much further (2013). Most anthropologists may take Malinowski's point, but to be honest, most of 
them don't really care what the Kiriwinan word buyagu actually means. But most anthropologists do care what the word politics means, often passionately so. When Goldman came to realize that his poor black informants in Southern Bahia shared absolutely none of his own meanings of this word, he became acutely aware that something was very wrong. How could the fragile new democracy of Brazil possibly ever work if his informants, probably representative of the vast majority of the voting population, hold such very different ideas of what democracy might actually mean? It is an empirical and ethnographic question.

What does the word Capanahua mean? This is Krokoszyński's question, and he correctly realizes that you cannot empirically answer it by finding a Capanahua person and simply asking them. That would elevate what you think the word means to a primary position, and render the answer distinctly secondary. But you can set out on an ethnographic project quite legitimately by taking what you think a word might mean to another person and using that fact as an opening gambit. That opening gambit will lead you to where a lot of people spend a lot of time debating the meaning of that word, and then get you to realize that the debate is what matters. What, Malinowski asked, do words mean?

\section{Acculturation}

What does the word acculturation actually mean? It is unlikely that anyone conversant with the anthropological literature on indigenous Amazonian peoples would be unfamiliar with the term or its basic meaning. Acculturated people are people who have lost their original culture through prolonged contact with another one. And this would be true even of those anthropologists with no particular commitment to a cultural anthropological concept of culture in the first place, far less to an analytically developed concept of acculturation. For Peruvian Amazonia, there are few if any studies of acculturation, and none where the concept is used as an analytically strong one: such studies were conducted in Brazil for a brief period. At most, acculturation functions as a kind of 'gate keeper' to acceptable and potentially profitable objects of ethnographic enquiry. After all, when faced with so much to study among the region's many and varied indigenous peoples, why waste time on studies that would likely yield little of genuine real interest?

But this is to misunderstand the history of acculturation as a concept, for the term has a fascinating history in studies of indigenous Amazonian peoples in German cultural anthropology. Beals, in his article on acculturation for the conference on Anthropology Today, noted with fine irony that the origins and growth of the concept of acculturation is "an instructive exercise for the student of culture change" (Beals 1953: 621). He wrote,

The term 'acculturation' is generally credited to American anthropologists. The occasional British student to refer to the word may concede its convenience but 
regards it with some horror. Paul Kirchhoff, however, has stated in conversation that the term was used in Germany by Walter Krickeberg in lectures somewhere in the mid-1920's to refer to the progress of development of a common basic culture among the tribes of diverse origin found on the upper Rio Xingu. (ibid.: 621)

In a footnote, Beals reports that Lowie pointed him towards the following passage by Krickeberg from 1910,

The constant intersecting currents of originally heterogeneous tribes brought about an extensive cultural equalisation (acculturation) through which the culture in the entire vast triangle between the Andes, Orinoco, Rio Negro and Madeira received a highly homogeneous character. (ibid.: 621, Fn 1; translation by Veronika Groke)

Quite unexpectedly, then, one of the original meanings of acculturation for anthropologists was precisely to describe a distinctive feature of 'un-acculturated' indigenous Amazonian peoples! That the indigenous peoples of the Upper Xingu river, among the ethnographically best known 'un-acculturated' indigenous peoples in Amazonia, were once held to be a perfect example of acculturation is a considerable surprise. A major cause for this surprise is due to the shifting intellectual agendas within the discipline. Who reads early German cultural anthropology today? Indeed, given the continuing retreat of the German language as a medium of international thought, how many specialists in the anthropology of Peruvian Amazonia even could read it? Mea maxima culpa, as my copy of Tessmann's Mensch ohne Gott taunts me with my extreme linguistic incompetence in relation to the wider regional literature (Tessmann 1928). So embarrassing was this revelation to me that I sat down and tried to teach myself German, to very limited effect, but it remains a key project for the future.

The implications are dramatic. If acculturation is what indigenous Amazonian people have historically been doing all along, and therefore that indigenous Amazonian sociality is profoundly marked by that fact, and deeply implicated in effectuating it, then we may need to seriously rethink what we are doing with our ethnographies. In particular, we need to seriously rethink the status of what categories like the Capanahua actually are. We imagine such categories to be specific cultures (or societies, if that term is preferred), that is, as the key units of study. We imagine such units to be the privileged objects of study, and that everything else comes after. But if we contemplate the older uses of acculturation, we begin to see that 'units' like the Capanahua may be historically derivative precipitates out of a very different field of indigenous Amazonian sociality. Viveiros de Castro in his 'GUT' article effectively makes this point, but does not really explore the ethnographic methodological problems it raises (2001). We are on very unfamiliar ground.

But we have help here, for exactly the same problem appears in the work of Malinowski as he founded anthropological fieldwork (of a certain kind, admittedly) as a scientific methodology. Malinowski found his method both with and against Rivers. As Malinowski wrote in his diary, 
Yesterday I understood the charm of 'survey study' à la Rivers, the encompassing of broad areas as a single whole. But this projection of space onto time (twodimensional or rather multi-dimensional entity) is very dangerous. (1968: 229-30)

There is no question that Malinowski's work on the Trobriand Islanders is a massive improvement on anything that Rivers wrote on The History of Melanesian Society (1914), and the injudicious projection of space onto time remains very dangerous. But this is not to deny that some of the large-scale patterns that Rivers identified are perfectly real, as demonstrated by the work of Marilyn Strathern when she wrote,

In the same way that one might wish to comprehend capitalist organisation as it developed historically in Europe, so one needs to inject a real history into our comprehension of Melanesian gift economies. The history itself may be irrecoverable, but we surely know enough about historical processes to recognise a series of connected events. (1988: 341)

Rivers' project for Melanesian anthropology has not gone away, but rather anthropologists since Malinowski have realized that the problems involved in fulfilling it are much more complicated than Rivers had thought.

\section{A new way of thinking}

In her Malinowski Lecture, 'The Soul's Body and its States', Anne-Christine Taylor suggested a possible Achuar theory of 'acculturation'. She sketched out an approach to the Achuar theory of being human that reconciles a broadly structuralist approach to ethnography with the cognitivist demands for psychological plausibility. She writes,

If my account of the Achuar person and selfhood as a repertoire of different states of being has more than local validity, then we will have to review our approach to the problem of acculturation. In particular, we must cease to think of acculturation as a gradual erosion and consequent reworking of the central beliefs of a culture. Among the Achuar, acculturation has in fact always been there, at the very core or 'middle ground' of the cultural system: it is not a matter of loss so much as the feeling of no longer being compelled to define the self by experiencing the whole range of states that it normally implies. Acculturation begins in a condition of being locked into a state of undefined or unmarked normality by no longer engaging in situations of interaction characteristic of the extreme states; thus an acculturated, or potentially acculturated, Jivaro is simply an ordinary being, what the Achuar themselves aptly call a nangami shuar, a 'just-so person', the kind of individual who can move in and out of his and other cultures with ease, provided he resides in their middle grounds of 'zero states'. (1996: 211) 
Taylor's account is an early step towards an ethnographic theory of acculturation, because she finds it fully within the Achuar lived world, rather than imposed exclusively from without.

One of the ugliest insults in the Piro language against another Piro person is kajitutatachri, 'one who habitually acts like a white person.' At first acquaintance with Piro people, one would be hard put to understand the sheer power of this insult. After all, don't most Piro people behave like white people most of the time (Gow 1991)? Isn't that what they are famous for? It would not be difficult to get their indigenous neighbours to say things like that, and many of them regularly do. But this is to profoundly misunderstand what Piro people mean by $k a-$ jitu, 'white man'. It is not a racial or ethnic category in the Euro-American sense, but rather refers to an attitude towards the world characterized by acquisitiveness, selfishness, failure to control anti-social emotions or to act on social emotions. It is to refuse to act upon the entirely reasonable claims by other people for the recognition of their humanity. The word kajitutatachri really means two things. Firstly, it refers to a Piro person who was taken away as a child and raised among white people, who when he or she returns is incapable of treating kinspeople correctly because they simply do not know how to do it: this is tragic, but little can be done about it. Secondly, it means, 'You fucking asshole!' This is when a Piro person who was demonstrably raised properly among Piro people acts towards other Piro people as if he or she wasn't. This is not at all tragic, but grounds for perfectly legitimate anger. This is another step on the way to an ethnographic theory of acculturation.

Krokoszyński's work is a major step towards such an ethnographic theory. What does it mean to be or not to be Capanahua, but on their grounds, rather than on ours? That is the question. How do we answer it? Just ask them, as Malinowski realized was perfectly possible in relation to the 'primitive economy' or the 'sexual life of savages'. What does it mean to be or not to be Capanahua? Just ask them. But in doing so, be aware that the replies may lead into new and unknown territory for anthropology.

\section{Bibliography}

Beals, R. (1953). Acculturation. In A.L. Kroeber (ed.), Anthropology Today (p. 621-41). Chicago: University of Chicago Press.

Goldman, M. (2013). How Democracy Works: An Ethnographic Theory of Politics. Canon Pyon: Sean Kingston Publishing.

Gow, P. (1991). Of Mixed Blood: Kinship and History in Peruvian Amazonia. Oxford Studies in Social and Cultural Anthropology. Oxford: Oxford University Press.

Malinowski, B. (1935). Coral Gardens and their Magic. London: George Allen and Unwin.

Malinowski, B. (1968). A Diary in the Strict Sense of the Term. New York: Harcourt, Brace and World Inc.

Rivers, W.H.R. (1914). The History of Melanesian Society. Cambridge: Cambridge University Press. 
Strathern, M. (1988). The Gender of the Gift: Problems with Women and Problems with Society in Melanesia. Berkeley, Los Angeles and London: University of California Press.

Taylor, A.-Ch. (1996). The soul's body and its states: an Amazonian perspective on the nature of being human. The Journal of the Royal Anthropological Institute (N.S.), 2(2), 201-15.

Tessmann, G. (1928). Menschen ohne Gott: Ein Besuch bei den Indianern des Ucayali. Stuttgart: Strecker und Schröder.

Viveiros de Castro, E. (2001). GUT Feelings about Amazonia: Potential Affinity and the Construction of Sociality. In L.M. Rival and N.L. Whitehead (eds.), Beyond the Visible and the Material: The Amerindianization of Society in the Work of Peter Rivière (p. 19-43). Oxford: Oxford University Press. 